\title{
Geociências
}

\section{Geometria e evolução do feixe de zonas de cisalhamento Manhuaçu - Santa Margarida, Orógeno Araçuaí, MG}

\author{
(Geometry and evolution of the Manhuaçu-Santa Margarida \\ shear zone system, Araçuai Orogen, MG)
}

\author{
Cláudio Maurício Teixeira da Silva \\ Departamento de Geologia, Escola de Minas, Univ.Federal de Ouro Preto.E-mail: claudiomts@gmail.com
}

Fernando Flecha Alkmim

Departamento de Geologia, Escola de Minas, Univ. Federal de Ouro Preto. E-mail: ffalkmim@gmail.com

Antônio Carlos Pedrosa-Soares

CPMTC-IGC-UFMG, Campus da Pampulha, Belo Horizonte.E-mail: pedrosa@pq.cnpq.br

\section{Resumo}

O Feixe de Zonas de Cisalhamento Manhuaçu-Santa Margarida de orientação geral NS estende-se por, aproximadamente, 300 km na região leste de Minas Gerais. Como uma das principais estruturas do núcleo cristalino do Orógeno Araçuaí, é constituído por um conjunto de zonas de cisalhamento dúcteis, que, em mapa, mostram traços sigmoidais. O seu segmento norte é composto por zonas de cisalhamento reversas que promovem o transporte de material em direção a oeste e, subordinadamente, por zonas transcorrentes dextrais. Os segmentos central e sul são dominados por zonas transcorrentes dextrais. O desenvolvimento do feixe deu-se em quatro fases deformacionais neoproterozóicas. A primeira fase promoveu a nucleação do conjunto de zonas reversas, que ficaram parcialmente preservadas no segmento norte do feixe. Durante a segunda fase, as zonas preexistentes experimentaram, de norte para sul, uma rotação progressiva para a vertical e para a direção NE-SW, além de intensa reativação transcorrente dextral. A terceira fase gerou zonas de cisalhamento normais de ocorrência restrita ao segmento norte. Na quarta fase, formaram-se falhas transversais e juntas. Em sua terminação sul, o feixe, dominado por zonas transcorrentes dextrais, rotaciona-se até confundir-se com as estruturas da porção NW da Faixa Ribeira. Tal fato implica que as estruturas dessa porção do feixe são de mesma idade, ou algo mais velhas que as transcorrências dextrais, que marcam o quadro tectônico do segmento NW da Faixa Ribeira.

Palavras-chave: Zonas de cisalhamento, transcorrência, Orógeno Araçuaí, Faixa Ribeira, Brasiliano.

\begin{abstract}
The N-S trending Manhuaçu-Santa Margarida shear zone system extends for ca. $300 \mathrm{~km}$ in eastern Minas Gerais. As one of the main structures of the crystalline core of the Neoproterozoic Araçuai Orogen, the Manhuaçu-Santa Margarida system is made up of a series of ductile shear zones, which show a sigmoidal trace in map view. The northern segment of the system mainly consists of west-verging thrusts and subordinate dextral strike-slip shear zones. The central and southern segments are dominated by dextral strike-slip shear zones. The development of the Manhuaçu-Santa Margarida system occurs in four distinct Neoproterozoic deformation phases. During the first phase, the system nucleated as a series of thrust shear zones, which remain preserved in the northern segment. During the second phase, the thrust zones experienced a clockwise rotation coupled with an intensive strike-slip reactivation, becoming vertical and NE-striking in the southern portion of the orogen. The third deformation phase generated normal-sense shear zones, observed only in the northern segment of the system. Brittle deformation along $W N W$-striking fault zones and jointing are the manifestations of the fourth and youngest deformation phase. The southern segment of the Manhuaçu-Santa Margarida system, dominated by dextral strike-slip zones, rotates progressively to a NE orientation and merges with the structures of the northwestern segment of the Ribeira belt. Therefore, the structures of the southern termination of the Manhuaçu-Santa Margarida system are of the same age or slight older than the dextral strike-slip shear zones that characterize the tectonic grain of the northwestern portion of the Ribeira Belt.
\end{abstract}

Keywords: Strike-slip shear zones, Araçuai orogen, Ribeira belt, Brasiliano. 


\section{Introdução}

O Orógeno Araçuaí localiza-se entre o Cráton do São Francisco e a margem continental leste brasileira, a norte da Faixa Ribeira, e corresponde à maior parte do Orógeno Araçuaí-Congo Ocidental. Constitui um dos vários componentes do sistema orogênico neoproterozóico originado durante a aglutinação do Gondwana Ocidental (PedrosaSoares et al., 2001, 2007, Alkmim et al., 2006, 2007). Do ponto de vista tectônico, o Orógeno Araçuaí compreende a faixa de dobramentos homônima (Almeida, 1977), situada na sua porção externa, e um núcleo, constituído por rochas graníticas e metamórficas de médio a alto grau. A porção sul do núcleo do orógeno possui, como estruturas mais proeminentes, quatro zonas de cisalhamento transcorrentes de expressão regional, denominadas zonas de Abre Campo, Manhuaçu-Santa Margarida, Guaçuí e Batatal (Figura 1). Como parte de um projeto de investigação tectônica sobre os sistemas de zonas transcorrentes da porção sul do Orógeno Araçuaí, o presente trabalho enfoca o aqui denominado Feixe de Zonas de Cisalhamento Manhuaçu-Santa Margarida. Após uma descrição da sua geometria geral, interpretamse a sua evolução e função cinemática. Com os resultados aqui apresentados, pretende-se contribuir para o entendimento da evolução do Orógeno Araçuaí e sua relação tectônica com a Faixa Ribeira, bem como para o entendimento da geometria e função cinemática de sistemas transcorrentes em orógenos de um modo geral.

\section{Estudos prévios sobre as zonas de cisalhamento Manhuaçu e Santa Margarida}

Costa et al. (1995, 1997 e 1998) chamaram de "Cinturão Transcorrente Manhuaçu" o conjunto de grandes lineamentos anastomosados de direção NS e NNE existentes entre Caratinga e Manhuaçu, em Minas Gerais. Para Costa et al. (1998), tais estruturas repre- sentariam, em Minas Gerais, a porção nordeste da Faixa Ribeira, a qual seria caracterizada pela alternância entre domínios tectônicos compressionais e transcorrentes. Zonas transcorrentes dextrais, que cortariam sistemas de empurrão mais antigos, representariam a última manifestação de uma colisão entre placas continentais durante o Neoproterozóico. Cunningham et al. (1998) postulam que a região de Manhuaçu exibiria um conjunto de falhas direcionais e oblíquas dextrais de direção NS, as quais comporiam estruturas em flor positiva, típicas de ambientes transpressivos. Noce et al. (2003) detectam entre as cidades de Cataguases e Miraí uma espessa zona de cisalhamento marcada por intenso retrometamorfismo.

\section{Características gerais do Feixe de Zonas de Cisalhamento Manhuaçu-Santa Margarida}

O Feixe de Zonas de Cisalhamento Manhuaçu - Santa Margarida configura uma faixa de direção preferencial nortesul, com inflexões para NE nas suas porções terminais. Compreende uma área entre os paralelos $18^{\circ} 45^{\prime}$ e $22^{\circ} 00^{\prime}$ e meridianos $41^{\circ} 45^{\prime}$ e $43^{\circ} 15^{\prime}$, entre as cidades de Governador Valadares, a norte, e de Juiz de Fora, a sul (Figuras 1, 3, 5 e 7). O feixe, que possui largura variável entre 15 e 40 km, baliza-se pela Zona de Cisalhamento de Manhuaçu, a leste, e pela Zona de Cisalhamento de Santa Margarida, a oeste. Exibe outros elementos de grande continuidade no seu interior, entre eles, as zonas de cisalhamento Realeza-Caratinga e São Sebastião do Batatal. Os litotipos por ele afetados pertencem a complexos infracrustais paleoproterozóicos (Mantiqueira ou Piedade, Juiz de Fora e Quirino), ao Complexo Pocrane (arqueano?), a unidades supracrustais (Andrelândia e Paraíba do Sul) e suítes granitóides (G1, pré-colisional, e G2, sincolisional) de idade neoproterozóica (Pedrosa-Soares et al., 2001, 2003, 2007, 2008; Signorelli, 2003; Ribeiro, 2002;
Tuller, 2002; Féboli \& Paes, 2002; Féboli, 2002; Noce et al., 2003, 2007, 2007b; Romano \& Noce 2003; Schobbenhaus et al., 2004). As zonas componentes do Feixe de Zonas de Cisalhamento Manhuaçu - Santa Margarida mostram traços anastomosados que isolam blocos alongados, de larguras variáveis entre 2 e $7 \mathrm{~km}$ (Figura 1). De um modo geral, os componentes do feixe expressam-se no relevo como vales alongados. A exceção fica por conta da Zona de Cisalhamento de Santa Margarida, que é marcada por altos topográficos, devido à ocorrência de rochas quartzíticas em grande parte de seu traçado. Na sua terminação norte, a paisagem associada ao Feixe de Zonas de Cisalhamento Manhuaçu Santa Margarida é caracterizada pela predominância de hogbacks; e nos segmentos central e sul, pelo predomínio de espigões alinhados, que lembram as formas do dorso de peixes (fishbacks, Figura 2).

Todos os componentes do feixe são de natureza dúctil e se materializam em rochas da série milonítica. A movimentação dos blocos é reversa e dirigida para oeste, no segmento norte, oblíqua, reversa-dextral, no segmento central, e essencialmente transcorrente dextral, no segmento sul. Em função disso, e também da sua geometria e história evolutiva, o Feixe de Zonas de Cisalhamento Manhuaçu - Santa Margarida pode ser subdividido em três domínios estruturais, os quais correspondem aos seus segmentos norte, central e sul (Figura 1).

\section{O segmento norte}

O segmento norte, compreendido entre as localidades de Governador Valadares e Ubaporanga (Figura 3), caracteriza-se pelo predomínio de zonas reversas em relação às zonas transcorrentes. Envolve três ramos principais que são contínuos por todo o domínio. $\mathrm{O}$ ramo leste corresponde à terminação do Feixe de Zonas de Cisalhamento de Manhuaçu; o central, à terminação da Zona de Cisalhamento São Sebastião do Batatal; e o oeste, à continuação da Zona de Cisalhamento de Realeza-Caratinga. 


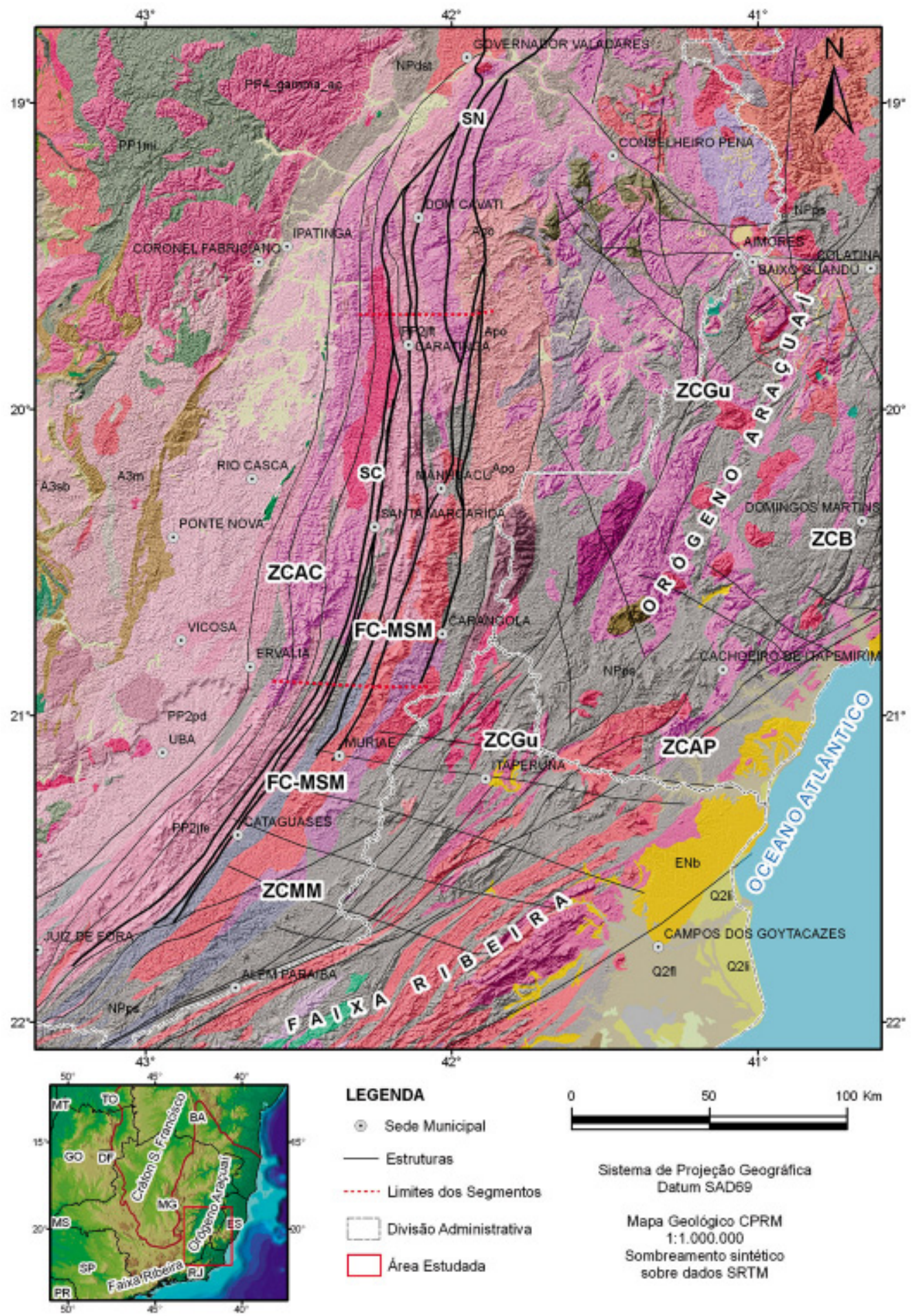

Figura 1 - Mapa geológico simplificado do Orógeno Araçuaí e porção nordeste da Faixa Ribeira mostrando a zona de cisalhamento de Abre Campo (ZCAC), o Feixe de Zonas de Cisalhamento Manhuaçu-Santa Margarida (FC-MSM), as zonas de cisalhamento Guaçuí (ZCGu), Batatal (ZCB), Maripá de Minas (ZCMM) e Além Paraíba (ZCAP). SN = Segmento Norte, SC = Segmento Central e SS = Segmento Sul. Mapa confeccionado com base em Schobbenhaus et al. (2004), onde: Apo = Complexo Pocrane, A3M/PP2pd = Complexo Mantiqueira/Piedade, PP2jft = Complexo Juiz de Fora (unidade tonalítica), PP2jfe = Complexo Juiz de Fora (unidade enderbítica), PP1mi = Grupo Itabira, NPps = Complexo Paraíba do Sul, NPdst = Formação S. Tomé, NP3a-Sga = tonalitos da Suite Galiléia, NP3a-1lbg = tonalito Bom Jesus do Galho (Suíte Galiléia), NP3a-2Ivn = tonalito Vermelho Novo, NP3a- Smu = Suíte Muriaé, ENb = Grupo Bareira e Q2 (fl e li) = depósitos do Quaternário. 


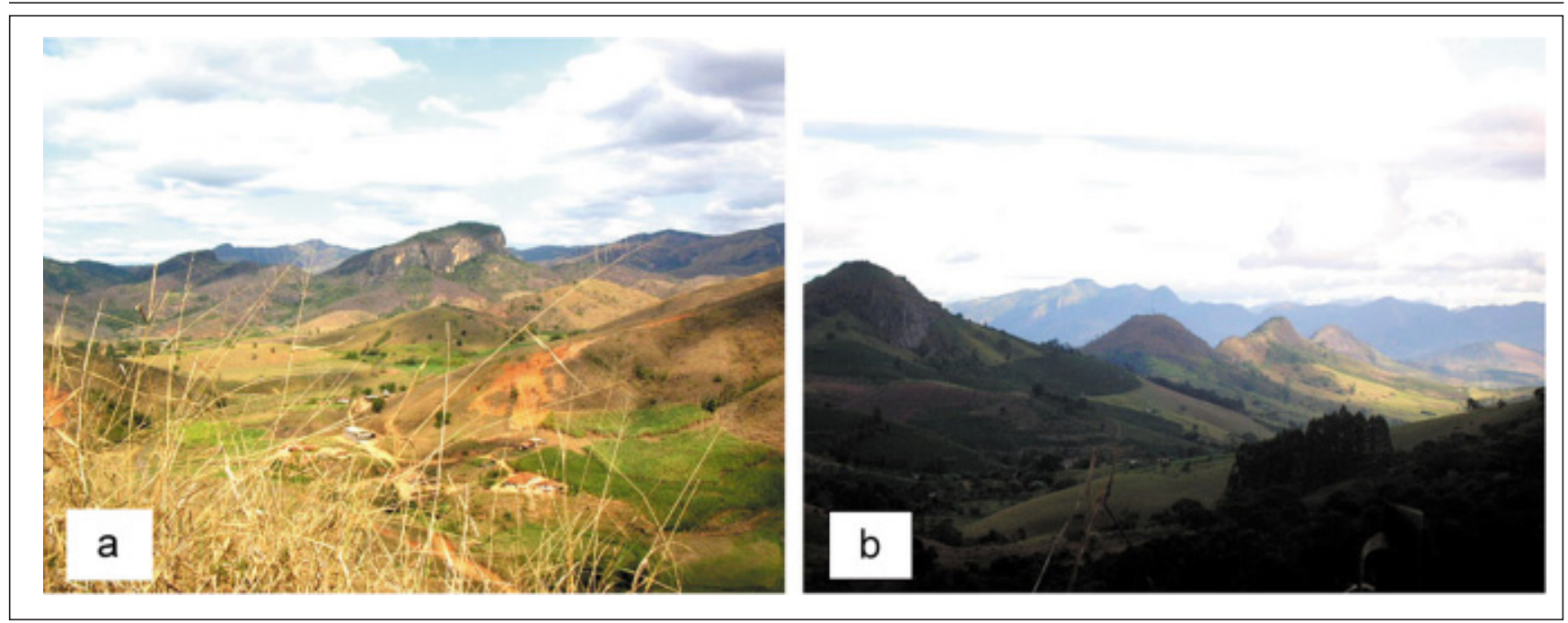

Figura 2 - Aspectos do relevo associado ao Feixe de Zonas de Zonas de Cisalhamento Manhuaçu-Santa Margarida (FC-MSM). a) Paisagem de hogbacks vista de NW, na região de Jerusalém-Novo Horizonte (MG), correspondente à porção norte do feixe. b) Espigões em dorso de peixe (“fishbacks"), alinhados na direção NNE- SSW, e vistos de NW, na região de Fortaleza-Divino, local conhecido como Serra de Fortaleza, porção central do feixe.

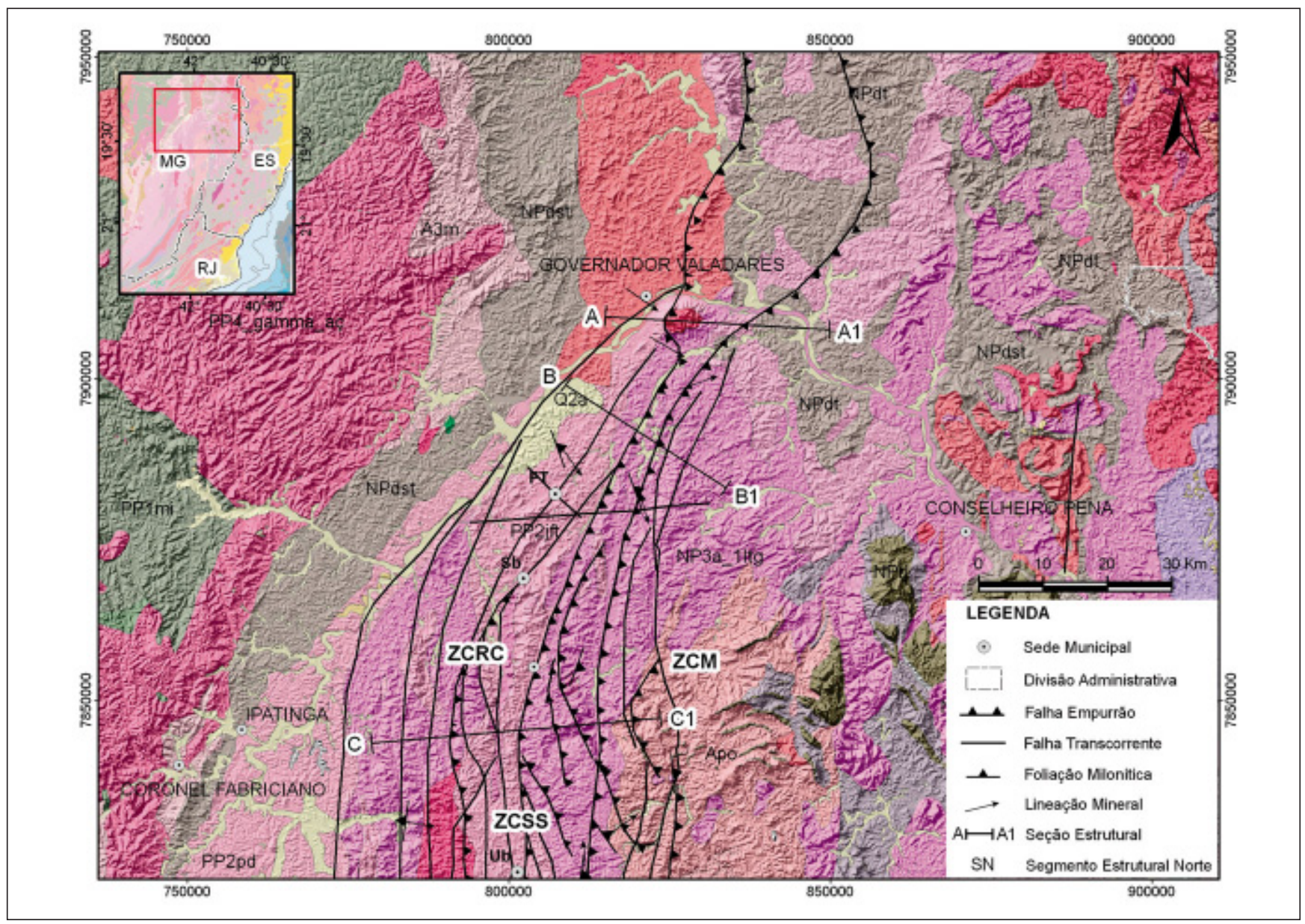

Figura 3 - Mapa geológico e localização das seções estruturais do segmento norte (SN) do Feixe de Zonas de Cisalhamento Manhuaçu - Santa Margarida (FC-MSM), confeccionado com base em Schobbenhaus et al. (2004), onde: Apo = Complexo Pocrane, A3M/PP2pd = Complexo Mantiqueira/Piedade, PP2jft = Complexo Juiz de Fora (unidade tonalítica), PP4-aç = Corpo Açucena, NP3a$1 \mathrm{ltg}$ = tonalitos da Suíte Galiléia (Sga), NPdt = Formação Tumiritinga, NPrj = Formação João Pinto e NPdst = Formação S. Tomé. Localidades: $\mathrm{FT}=$ Fernandes Tourinho, $\mathrm{Sb}=$ Sobrália e Ub = Ubaporanga. ZRC = Zona de Cisalhamento Realeza-Caratinga, ZCSS = Zona de Cisalhamento São Sebastião do Batatal e ZCM = Zona de Cisalhamento Manhuaçu. 
Cláudio Maurício Teixeira da Silva et al.

Movimentos essencialmente transcorrentes ocorrem, em parte, nos ramos central e oeste. Zonas de cisalhamento reversas com traços curvos em mapa se articulam aos ramos mencionados e são comuns por todo o segmento. Esse segmento é cortado, na região de Fernandes Tourinho e Sobrália, por um conjunto de falhas transcorrentes de direção NW-SE, bem como por um sistema de juntas de direções ENE e ESE.

Nas seções levantadas nesse segmento (Figuras 4a, 4b e 4c), observa-se que as zonas de cisalhamento possuem mergulhos variáveis para leste e passam de predominantemente reversas, a norte, para transcorrentes, a sul. A foliação (Figura 4d) mostra a orientação preferencial 109/25 e a lineação de estiramento (Figura 4e) tem como orientações mais freqüentes 077/35 e 000/05, características de movimentações reversas e direcionais, respectivamente. Os indicadores cinemáticos incluem dobras assimétricas, sigmóides (pods) de foliação e porfiroclastos assimétricos. A seção $\mathrm{AA}_{1}$ (Figura 4a) contém quatro zonas de empurrão mergulhantes para leste, as quais se associam a grandes dobras rompidas. O Pico do Ibituruna tem na base o Tonalito Derribadinha da Suite G1 (précolisional) e, no ponto culminante, um corpo granítico foliado da Suíte G2 (sincolisional). O Tonalito Derribadinha (Suíte Galiléia) está gnaissificado, com veios aplíticos centimétricos discordantes, dobrados e boudinados. A foliação apresenta dobras apertadas e desarmônicas, vergentes para oeste e, também, com trajetória sigmoidal, contornando amêndoas simétricas e assimétricas. $\mathrm{O}$ granitóide do Pico do Ibituruna é homogêneo, de cor cinza-claro a róseo, de granulação fina a média e contém diques centimétricos de pegmatóides. Nos arredores de Governador Valadares, os movimentos evidenciados pelas foliações e lineações variam entre reverso-dextrais, a sul, e sinistral-reversos, a norte. Para leste, ocorre o Tonalito Galiléia (Suíte G1), gnaissificado e milonitizado, no qual, localmente, a foliação toma um aspecto sigmoidal e os veios pegmatíticos ficam boudinados. Zonas de cisalhamento normais, afetando a foliação dominante, podem ser observadas na região (Cunningham et al., 1996, Nalini et al., 2000). A seção $\mathrm{BB}_{1}$ (Figura 4b) atravessa zonas reversas e transcorrentes, que cortam rochas dos complexos Mantiqueira, Juiz de Fora e Pocrane, além do Tonalito Derribadinha (Figura 3c). Nas zonas de cisalhamento, as rochas encontram-se milonitizadas, em maior ou menor intensidade, e dobradas. Na seção $\mathrm{CC}_{1}$ (Figura 4c), ocorrem, de oeste para leste, o Tonalito Bom Jesus do Galho, Complexo Juiz de Fora, Tonalito Derribadinha e Complexo Pocrane (Féboli, 2002, Féboli et al., 2002, Tuller, 2002). A leste da BR-116, a seção é dominada por zonas reversas, onde o relevo característico é caracterizado por hogbacks. Zonas transcorrentes dextrais predominam a oeste. No interior das zonas de cisalhamento, as rochas estão normalmente milonitizadas, exibindo cristais de granada milimétricos, sin-cinemáticos à foliação. Localmente, essas rochas apresentam sigmóides de foliação, dobras de arrasto e intrafoliais.

\section{O segmento central}

O segmento central estende-se de Caratinga, a norte, até as proximidades de Ervália-Carangola a sul, com uma largura variável entre 20 e $30 \mathrm{~km}$ (Figura 5). As zonas de cisalhamento, de direções predominantemente norte-sul, são contínuas por toda sua extensão e exibem, em mapa, traços anastomosados. O espaçamento entre os traços das zonas constituintes é de $1 \mathrm{~km}$, no mínimo, a $8 \mathrm{~km}$, no máximo. As zonas transcorrentes predominam no interior do feixe, ao passo que as reversas estão restritas às suas bordas. A atitude modal das foliações (Figura 6d) é de 097/80 e as lineações orientam-se preferencialmente em torno de 015/24 (Figura 6e).

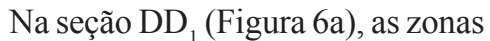
reversas principais estão na sua porção ENE e lançam rochas do Complexo Pocrane sobre o Tonalito Derribadinha (Suíte Galiléia). Outras zonas reversas ocorrem a leste de Caratinga e BR-116, onde são cortadas pela zona de cisalhamento transcorrente de Realeza-Caratin- ga, que corresponde à zona de deslocamento principal de uma estrutura em flor positiva, bem exposta no segmento da BR-116, que passa por essa área. As duas zonas da extremidade WSW da seção correspondem às zonas de cisalhamento de Abre Campo (Peres et al., 2004) e Matipó (Cunningham et al., 1998). Entre Caratinga e São João da Jacutinga, está a Zona de Cisalhamento de São Sebastião do Batatal, que se conecta à de Manhuaçu a sul dessa seção, próximo à localidade de Alegria. Os diversos litotipos estão milonitizados nas proximidades dessas zonas e se apresentam, localmente, com sigmóides de foliação. Grandes dobras intrafoliais são os elementos mais comuns entre os traços das zonas de cisalhamento. A seção $\mathrm{FF}_{1}$ (Figura $6 \mathrm{~b}$ ) envolve rochas das unidades Juiz de Fora e Andrelândia, a oeste, e Pocrane, a leste. Estão presentes, nessa seção, zonas reversas reativadas e transcorrentes, com predomínio das últimas sobre as primeiras. Os litotipos encontram-se milonitizados nas zonas de cisalhamento, exibindo pods de foliação, dobras apertadas, porfiroclastos de feldspatos e cristais de granadas rotacionados e mobilizados pegmatóides. Nos intervalos entre as zonas, são comuns megadobras vergentes para oeste. $\mathrm{Na}$ altura de Realeza, ocorre a zona principal de uma grande estrutura em flor positiva, uma vez que os caimentos das zonas vizinhas para aí convergem. A Zona de Cisalhamento de Santa Margarida, a oeste, pode ser seguida nas linhas de cumeadas dos morros por cerca de $200 \mathrm{~km}$, desde Santa Bárbara, a norte, até as proximidades de Argirita, a sul. Ao longo de toda sua extensão, há inúmeros pontos de extração de saibro, as "saibreiras" da região, as quais se caracterizam pela exposição do produto de alteração supergênica de intercalações métricas de faixas ricas em quartzo e faixas ricas em feldspatos. Tais massas apresentam-se com o aspecto de megaribbons, descritos na literatura em escala de lâminas (e.g., Hippertt et al., 2001). Nesta zona, a foliação (Figura 6d) orienta-se preferencialmente segundo 080-100/60-85, com lineações de estiramento (Figura 6e) subori- 
a)
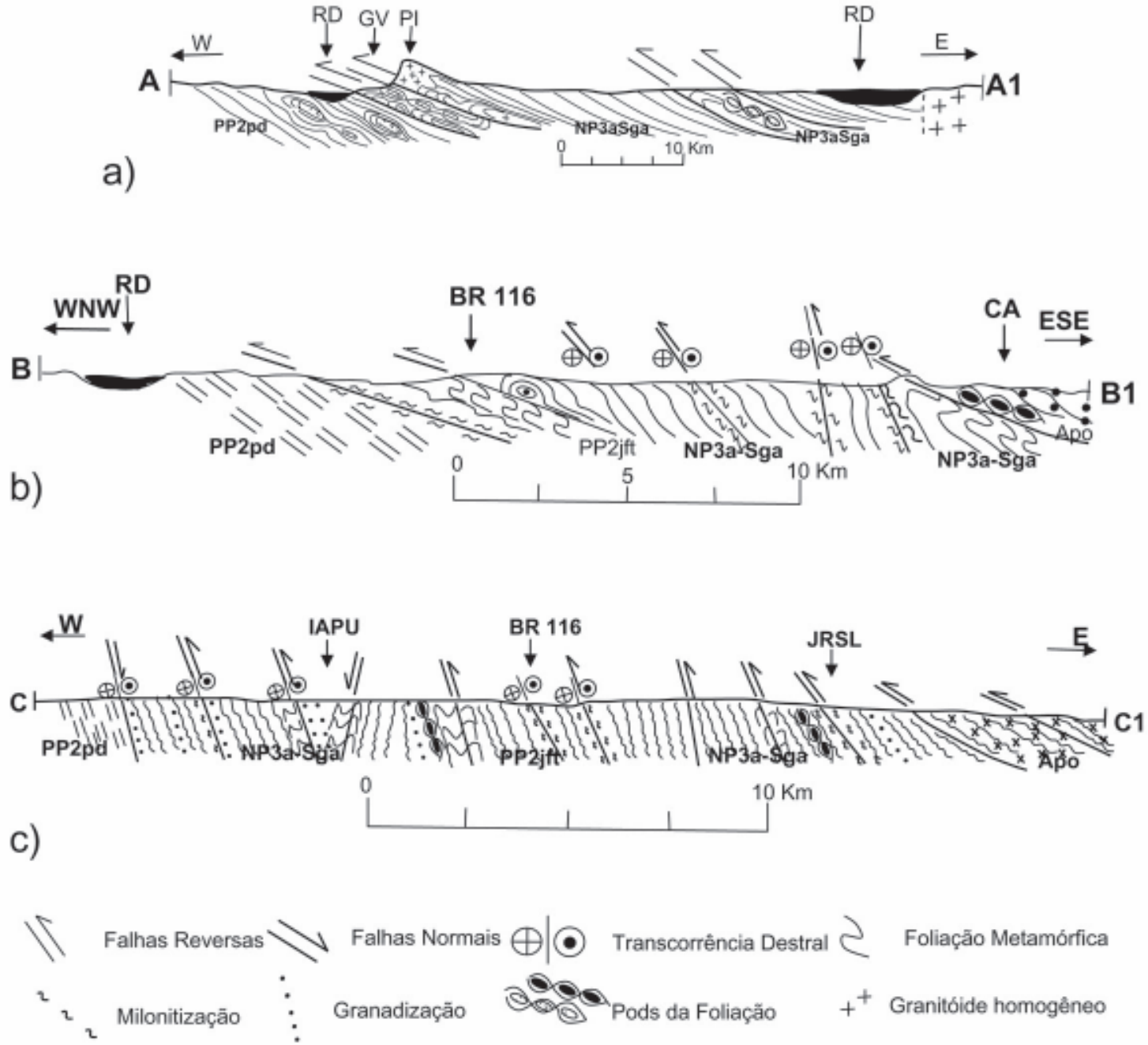

$\mathrm{RD}=$ Rio Doce $\mathrm{GV}=$ Governador Valadares $\mathrm{PI}=$ Pico do Ibituruna $\quad \mathrm{CA}=$ Capitão Andrade JRSL = Jerusalém

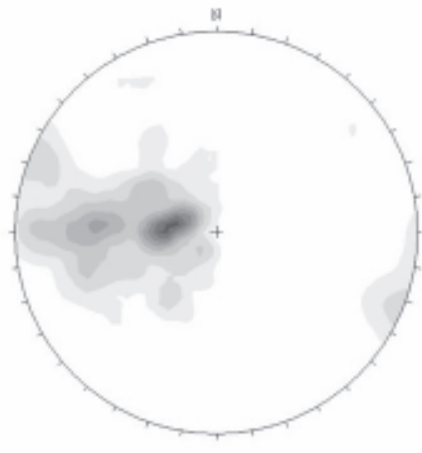

d)

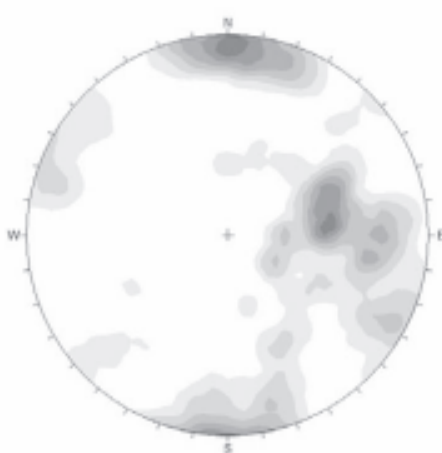

e)

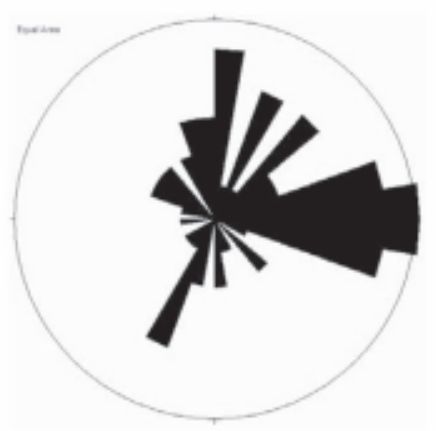

$\mathrm{N}=71$

Méd. = ENE e ESE

Figura 4 - Seções geológico-estruturais através do segmento norte do Feixe de Zonas de Cisalhamento Manhuaçu - Santa Margarida e diagramas com a representação estatística das principais estruturas. a) seção estrutural AA1; b) seção estrutural BB1; c) seção estrutural $\mathrm{CC} 1$; d) estereograma da foliação metamórfica; e) estereograma da lineação mineral e f) diagrama de roseta das juntas. A posição das seções encontra-se no mapa da Figura 3. 
Cláudio Maurício Teixeira da Silva et al.

zontais (355-010/13-25) ou de alta obliqüidade (053-100/62-65). As juntas (Figura 6f) que ocorrem nesse domínio constituem um conjunto de orientação preferencial ENE e um par conjugado cisalhante de direções ENE-WSW e WNWESE. A seção $\mathrm{HH}_{1}$ corta os mesmos litotipos da seção anterior. Ela mostra uma zona reversa na extremidade leste e zonas transcorrentes dextrais nas demais porções. A leste da seção ocorrem granada charnoquitos (neoproterozóicos?), que mostram granulação fina a grossa, com enclaves máficos e, localmente, bandamento gnáissico incipiente com caimento para ENE (075/30). As juntas, nesse domínio, têm direções predominantes WNW-ESE e, secundariamente, ENEWSW.

\section{O segmento sul}

O segmento sul envolve rochas das unidades Juiz de Fora, Quirino e Paraíba do Sul, além de granitóides neoproterozóicos (Figura 7). Caracteriza-se por um conjunto de zonas transcorrentes subparalelas de direção NE-SW, com espaçamentos que variam entre 1 a $7 \mathrm{~km}$ e cuja largura média fica em torno de $30 \mathrm{~km}$. Uma única zona reversa foi identificada na borda nordeste do domínio. As foliações mostram forte caimento para SE e a sua orientação preferencial é 125/77 (Figura 8d). As lineações exibem a atitude modal de 035/05 (Figura 8e). As juntas que ocorrem nesse segmento estão preferencialmente orientadas na direção NW-SE (Figura 8f). A terminação sul do feixe dá-se por uma diminuição progressiva de sua largura, com a perda de definição de vários de seus elementos. A Zona de Cisalhamento de Manhuaçu desaparece nas proximidades de Muriaé

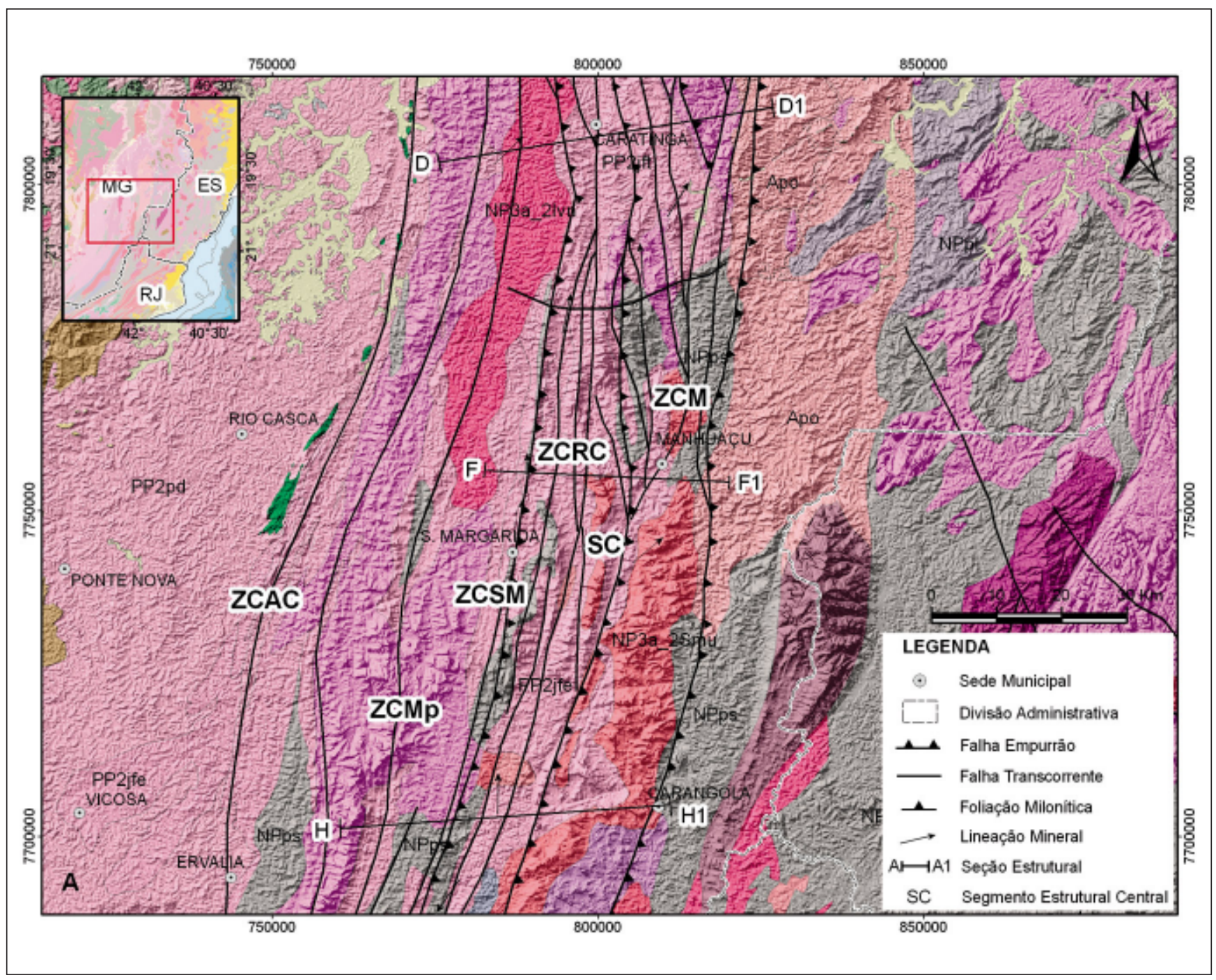

Figura 5 - Mapa geológico e seções do segmento central (SC) do Feixe de Zonas de Cisalhamento Manhuaçu - Santa Margarida confeccionado com base em Schobbenhaus et al. (2004), onde: Apo = Complexo Pocrane, PP2pd = Complexo Mantiqueira/Piedade, PP2jft = Complexo Juiz de Fora (unidade tonalítica), PP2jfe = Complexo Juiz de Fora (unidade enderbítica), NPps = Complexo Paraíba do Sul, NPpl = Formação Palmital do Sul, Np3a-1lbg/Sga = tonalito Bom Jesus do Galho (Suíte Galiléia), NP3a-2lvn = tonalito Vermelho Novo e NP3a- Smu = Suíte Muriaé. Zonas de Cisalhamento: Abre Campo (ZCAC), Matipó (ZCMp), Santa Margarida (ZCSM), RealezaCaratinga (ZCRC) e Manhuaçu (ZCM). 


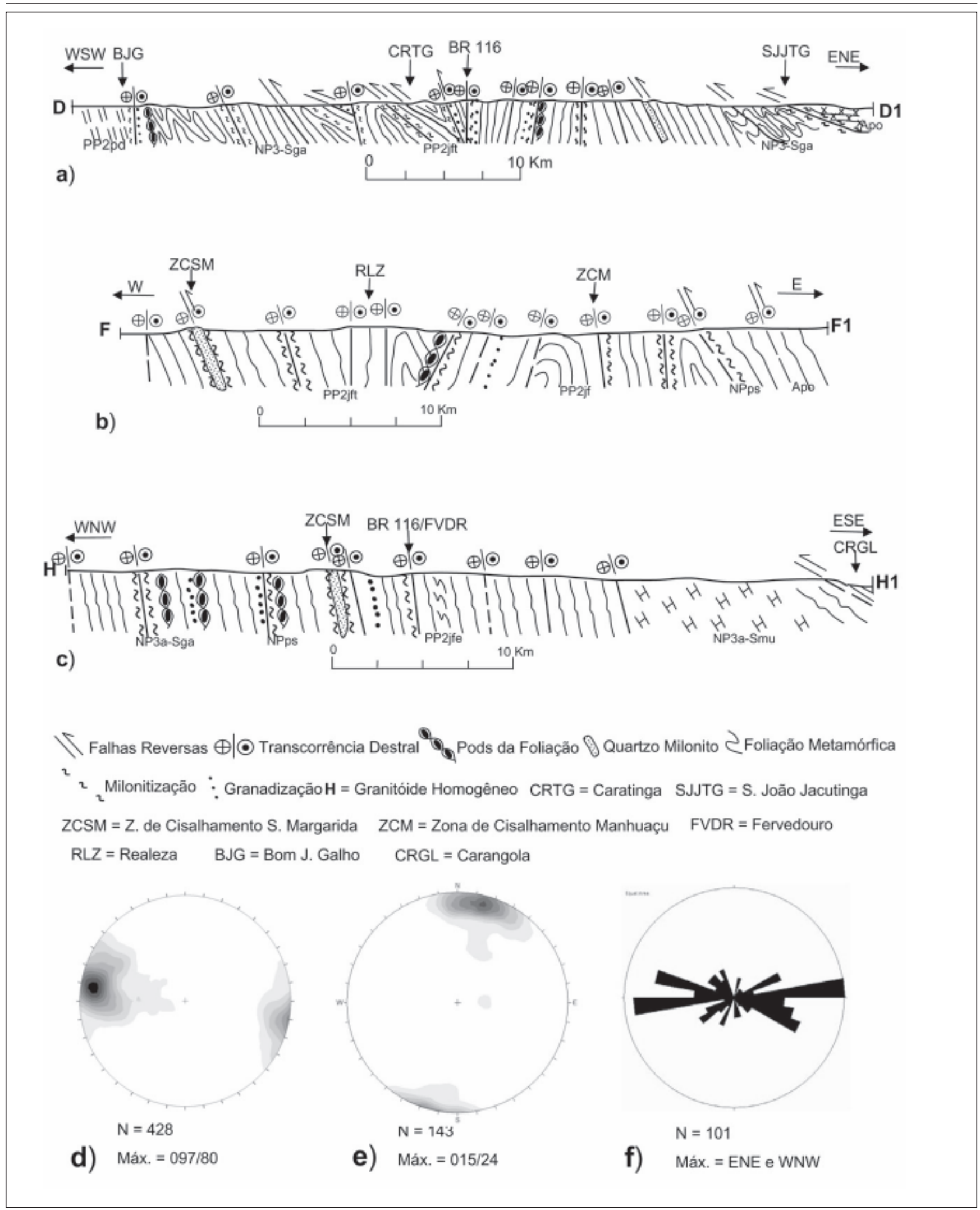

Figura 6 - Seções geológico-estruturais através do segmento central do Feixe de Zonas de Cisalhamento Manhuaçu - Santa Margarida e diagramas com a representação estatística das principais estruturas. a) seção estrutural DD1; b) seção estrutural FF1; c) seção estrutural $\mathrm{HH}$; d) estereograma da foliação metamórfica; e) estereograma da lineação mineral e f) diagrama de roseta das juntas. A posição das seções encontra-se no mapa da Figura 5. 
Cláudio Maurício Teixeira da Silva et al.

e a de Realeza-Caratinga desaparece a nordeste de Cataguases. A partir de Miraí, permanece apenas a Zona de Cisalhamento de Santa Margarida, que, por sua vez, é truncada por uma zona de cisalhamento trancorrente dextral de orientação ENE-WSW, aqui denominada Zona de Cisalhamento Maripá de Minas (Figura 7). Essa zona, em virtude de sua orientação cinemática e associação com elementos tectônicos de mesmas características, é aqui vista como elemento característico da Faixa Ribeira, ou seja, a terminação sul do Feixe de Cisalhamento Manhuaçu - Santa Margarida caracteriza-se como um truncamento por elementos característicos da Faixa Ribeira.
A seção $\mathrm{JJ}_{1}$ (Figura 8a) atravessa rochas das unidades Mantiqueira, Juiz de Fora, Quirino e Paraiba do Sul, além de granitóides neoproterozóicos da Suíte Muriaé. A seção KK 1 (Figura 8b) atravessa praticamente os mesmos litotipos da seção anterior e uma série de zonas transcorrentes dextrais. A seção LL1 (Figura 8c) atravessa os litotipos dos complexos Juiz de Fora e Quirino e Paraíba do Sul. Na região leste de Juiz de Fora, são comuns as saibreiras instaladas em rochas quartzo feldspáticas alteradas e friáveis. Em uma dessas saibreiras, foram encontradas rochas menos alteradas, nas quais os megaribbons de quartzo apresentam-se em dobras intrafoliais rompidas.

\section{Evolução do feixe de zonas de cisalhamento Manhuaçu - Santa Margarida}

Tomando por base as relações de corte e superposição observadas no campo entre os elementos estruturais presentes no interior do feixe, quatro fases de deformação podem ser caracterizadas. A mais antiga $\left(D_{n}\right)$ é representada por zonas de cisalhamento reversas e dobras assimétricas, as quais se associam a uma foliação penetrativa em todas as escalas e conspícua lineação de estiramento posicionada na direção de

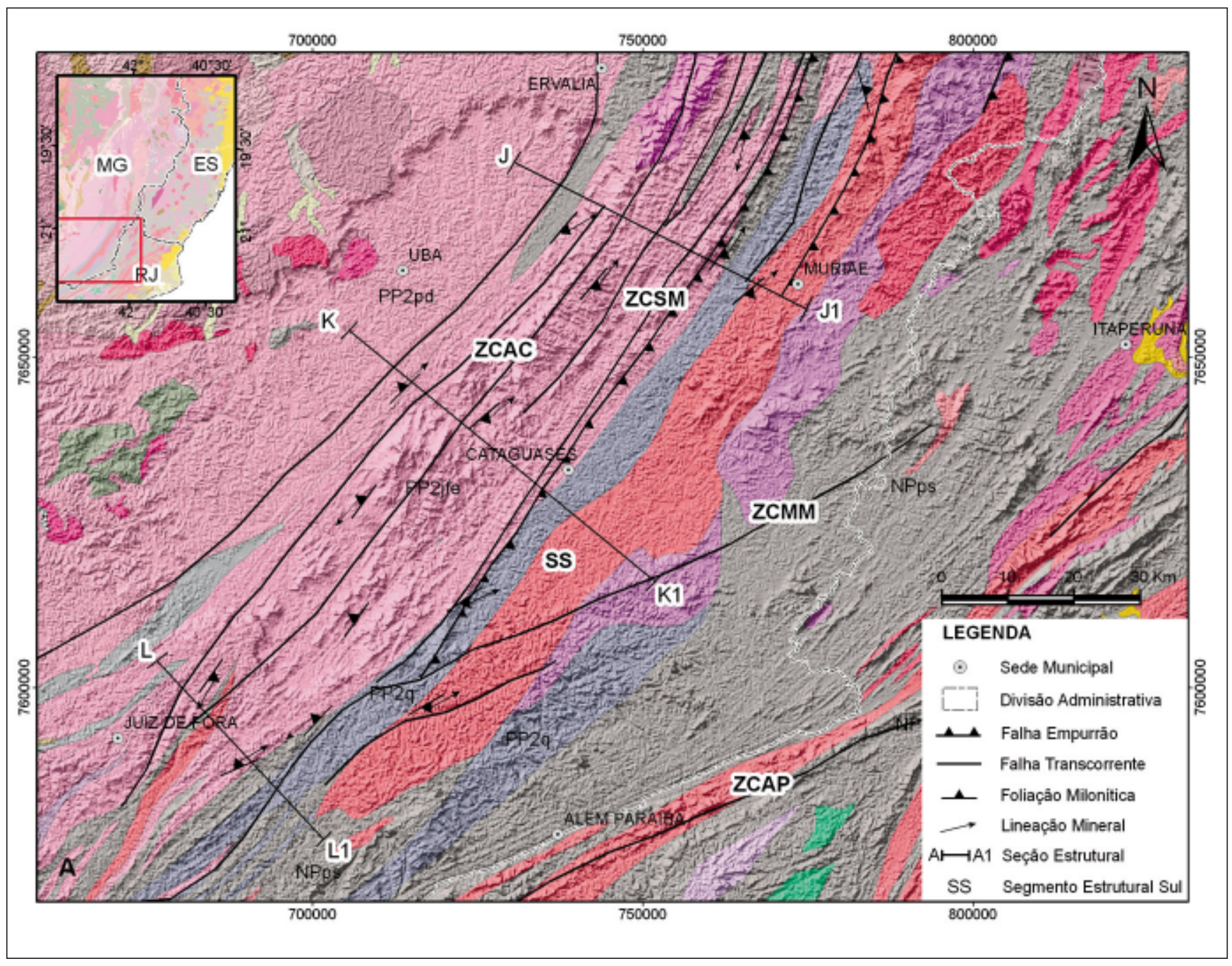

Figura 7 - Mapa geológico e seções do segmento sul (SS) do Feixe de Cisalhamento Manhuaçu - Santa Margarida (FC-MSM), confecionado com base em Schobbenhaus et al. (2004), onde: PP2pd = Complexo Mantiqueira/Piedade, PP2jfe = Complexo Juiz de Fora (unidade enderbítica), PP2q = Complexo Quirino, NPps = Complexo Paraíba do Sul e NP3a-2Smu = Suíte Muriaé. Zonas de Cisalhamento: Abre Campo (ZCAC), Santa Margarida (ZCSM), Maripá de Minas (ZCMM) e Além Paraíba (ZCAP). 

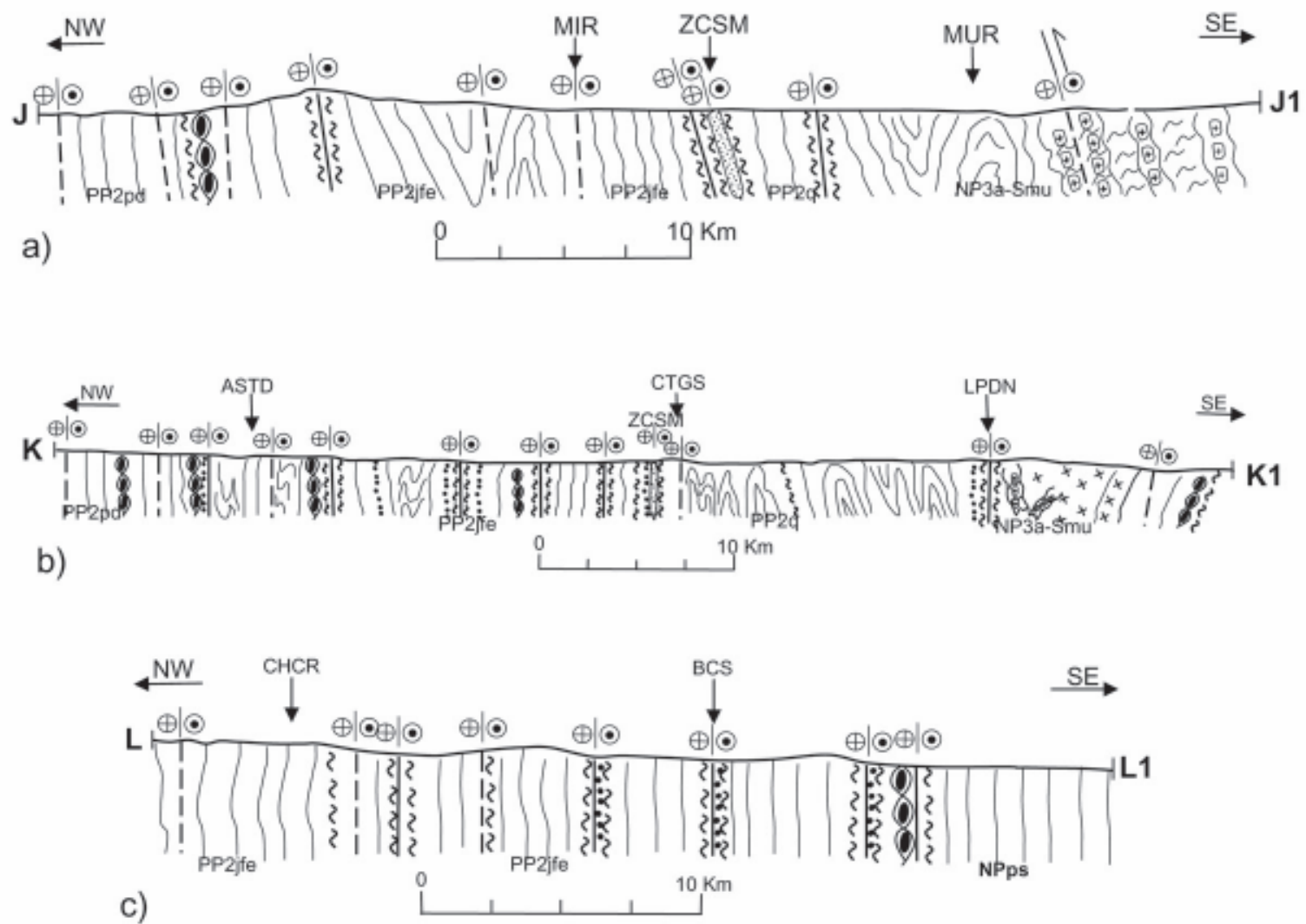

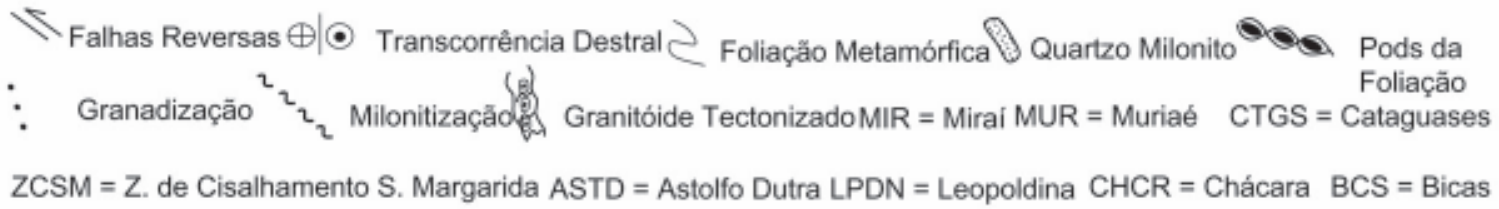

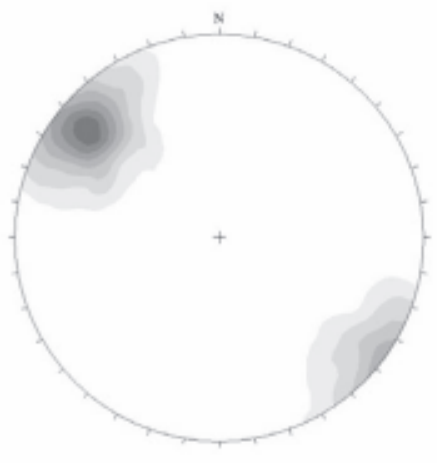

d)

$$
\mathrm{N}=284
$$

Máx. $=125 / 77$

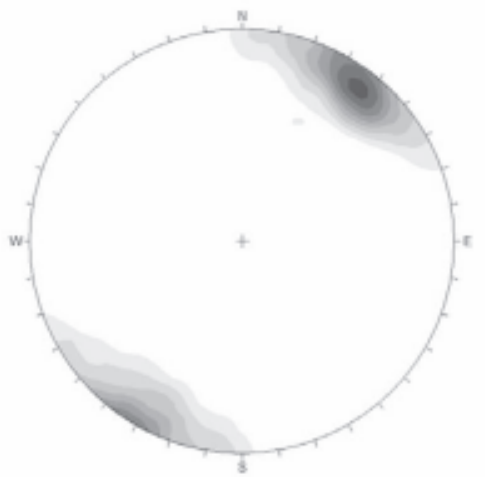

e) $\quad \mathrm{N}=125$

Máx. $=035 / 05$

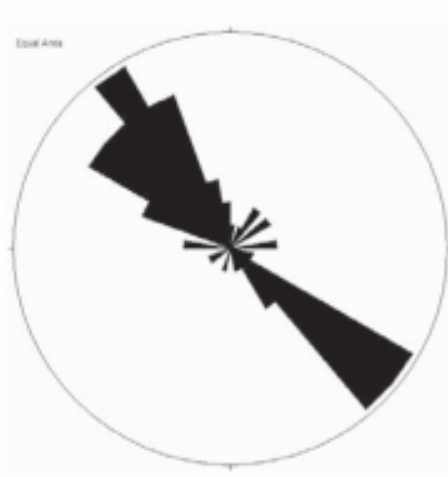

f) $\quad \mathrm{N}=77$

Méd. $=$ NW-SE

Figura 8 - Seções geológico-estruturais através do segmento sul do Feixe de Zonas de Cisalhamento Manhuaçu - Santa Margarida e diagramas com a representação estatística das principais estruturas: a) Seção estrutural JJ1; b) Seção estrutural KK1; c) Seção estrutural LL1; d) Estereograma da foliação metamórfica; e) Estereograma da lineação mineral e f) Diagrama de roseta das juntas. A posição das seções encontra-se no mapa da Figura 7. 
mergulho da foliação. Todos os seus elementos refletem transporte tectônico dirigido sistematicamente para oeste, sob a ação de um campo compressivo de orientação geral E-W e nas condições da fácies anfibolito a granulito. A segunda fase de deformação $\left(D_{n+1}\right)$ foi responsável pela formação de zonas de cisalhamento dúcteis transcorrentes e pela rotação e reativação das zonas de cisalhamento preexistentes, também como zonas transcorrentes dextrais. A estas zonas associam-se foliações miloníticas verticais a subverticais, lineações de estiramento direcionais, além de várias estruturas de pequena escala que servem como indicadores cinemáticos. Essa fase desenvolveu-se nas condições metamórficas da fácies xisto verde a anfibolito. A terceira fase de deformação $\left(D_{n+2}\right)$ gerou zonas de cisalhamento normais de ocorrência restrita ao segmento norte. Tais zonas nucleram-se, principalmente, por reativação de zonas mais antigas, de modo que sua orientação preferencial, reproduz aquela das estruturas anteriormente descritas. A quarta fase $\left(\mathrm{D}_{\mathrm{n}+3}\right)$ é de natureza rúptil e foi responsável pela formação de falhas e juntas com as orientações preferenciais EW e NNE-SSW, no segmento norte; ENE-WSW e WNWESE, no segmento central; e NW-SE, no segmento sul. Pegmatitos e outros veios quartzo-feldspáticos, de espessuras decimétricas a métricas, podem estar encaixados em tais falhas e juntas. $\mathrm{O}$ fato de o Feixe de Zonas de Cisalhamento Manhuaçu - Santa Margarida, como um todo, tornar-se, em direção a sul, progressivamente dominado pelas estruturas transcorrentes $\mathrm{D}_{\mathrm{n}+1}$ e coalecer-se com a trama da Faixa Ribeira, que na sua porção norte é também dominada por estruturas transcorrentes dextrais de orientação NE-SW (Pedrosa-Soares et al., 2003), tem duas implicações importantes. Em primeiro lugar, pode-se afirmar que as zonas dextrais do feixe são mais velhas ou, mais provavelmente, de mesma idade das estruturas dominantes da porção norte da Faixa Ribeira. Em segundo lugar, pode-se também afirmar que, do ponto de vista estrutural, o limite en- tre o Orógeno Araçuaí e a Faixa Ribeira, na região enfocada, pode ser posicionado ao longo da zona de cisalhamento de Maripá de Minas (ZCMM), orientada a NE-SW, que baliza o feixe pelo sul.

\section{Discussão e conclusões}

A maioria dos autores que estudaram a região afetada pelo Feixe de Zonas de Cisalhamento Manhuaçu - Santa Margarida postulou a atuação de três fases deformacionais, com a geração das transcorrências dextrais dando-se posteriormente a uma fase compressional principal (Costa et al.,1995 e 1998; Fischel, 1998; Cunningham et al., 1996, 1998; Signorelli, 2002; Tuller, 2002; Noce et al., 2003; Romano \& Noce, 2003; Peres et al., 2004). Alkmim et al. (2006, 2007), em um modelo evolutivo do Orógeno Araçuaí-Congo Ocidental, propõem que, na porção sul do Orógeno Araçuaí, após a etapa sincolisional, teriam se formado as zonas trancorrentes dextrais, que, entre 560 e $535 \mathrm{Ma}$, promoveriam o escape lateral de massas em direção a SW. Em virtude do grande espessamento litosférico adquirido nas fases precedentes, o orógeno experimentaria colapso gravitacional entre 520 e $490 \mathrm{Ma}$, acompanhado de intrusão de grande volume de granitos pós- colisionais.

Em função do exposto, vê-se que os resultados aqui obtidos relativos à evolução do Feixe de Zonas de Cisalhamento Manhuaçu - Santa Margarida estão em acordo com a maioria dos estudos previamente realizados em partes de sua zona de ocorrência. Eles permitem, também, que as seguintes conclusões sejam tiradas:

- O Feixe de Zonas de Cisalhamento Manhuaçu-Santa Margarida, com um traço sigmoidal em mapa, uma largura média de $22 \mathrm{~km}$ e um comprimento de aproximadamente $300 \mathrm{~km}$, é constituído por um conjunto de zonas dúcteis de empurrão e transcorrências dextrais.
- A sua terminação norte dá-se na altura da cidade de Governador Valadares, onde é francamente dominado por falhas de empurrão. A sua terminação sul, caracterizada por transcorrências dextrais, é marcada por uma progressiva rotação para a direção NE e coalescência com zonas transcorrentes dextrais dominantes na porção noroeste da Faixa Ribeira.

- A evolução do feixe deu-se em quatro fases. A sua nucleação como um conjunto de zonas dúcteis de empurrão deu-se durante etapa colisional principal do Orógeno Araçuaí, entre 585 e $560 \mathrm{Ma}$ (Pedrosa-Soares et al., 2001, 2007) e foi acompanhada de metamorfismo regional e produção de granitos anatéticos nas condições da fácies anfibolito e granulito. A seguir, o conjunto foi rotacionado para a posição vertical e para a direção NE-SW e reativado, em intensidades crescentes de norte para sul, por movimentos direcionais dextrais. Nessa segunda etapa evolutiva, que ocorreu provavelmente entre 560 e $535 \mathrm{Ma}$, a deformação, também em regime dúctil, foi acompanhada de reações metamórficas típicas da fácies anfibolito baixo a xisto verde. Outras estruturas associadas ao feixe são zonas de cisalhamento dúctil-rúpteis normais, falhas transcorrentes de direção preferencial WNWESSE e juntas, atribuíveis a duas fases mais jovens.

- Enfatiza-se que o Feixe de Zonas de Cisalhamento Manhuaçu-Santa Margarida é truncado pelas estruturas da Faixa Ribeira, situada a sul do Orógeno Araçuaí. Os elementos do feixe, rotacionando-se progressivamente para a direção NE-SW, confundem-se e são localmente truncados pelas estruturas dominantes da porção NW da Faixa Ribeira. Tal fato implica que as estruturas dessa porção da Faixa Ribeira, também transcorrências dextrais, são de mesma idade ou mais jovens que os elementos tectônicos dominantes do segmento sul do Feixe de Cisalhamento Manhuaçu-Santa Margarida. 


\section{Agradecimentos}

Os autores agradecem o apoio financeiro recebido do CNPq através dos projetos 477618/2003-0 e 478960/2006-9, e ao Programa de Pós-Graduação do DEGEO-UFOP que ofereceu infra-estrutura e apoio logístico para o desenvolvimento do presente estudo. Os autores Fernando F. Alkmim e A.C. Pedrosa Soares agradecem ao CNPq pelas bolsas de produtividade em pesquisa.

\section{Referências bibliográficas}

ALKMIM, F.F., MARSHAK, S., PEDROSA-SOARES, A.C., CRUZ, S., PERES, G.G., CRUZ, S.C.P., WHITTINGTON, A. Kinematic evolution of the Araçuaí-West Congo orogen in Brazil and Africa: Nutcracker tectonics during the Neoproterozoic assembly of Gondwana. Precambrian Research, n.149, p. 43-64, 2006.

ALKMIM, F.F., PEDROSA-SOARES, A.C., NOCE, C.M., CRUZ, S.C.P. Sobre a evolução tectônica do Orógeno AraçuaíCongo Ocidental. Revista Geonomos, v. 15, n. 1, p. $25-43,2007$.

ALMEIDA, F.F.M. O Cráton do São Francisco. Revista Brasileira de Geociências, v. 4, p. 349-364, 1977.

COSTAA.G., ROSIERE, C.A., MOREIRA, L.M., FISCHEL, D.P. Caracterização geotectônica do setor setentrional do Cinturão Ribeira: evidência de acresção neoproterozóica no leste de Minas Gerais, Brasil. Revista Geonomos, v. 3, p. 51-68, 1995 .

COSTA, A.G., ROSIERE, C.A., EBERT, H.D., FISCHEL, D.P. Macroestruturação da região leste de Minas Gerais. In: SBG, Simp. Nac. Est. Tectôn., 6. Resumos Expandidos: p. 285-287, 1997.

COSTA, A.G., ROSIERE, C.A., EBERT, H.D., FISCHEL, D.P., FUCK, R.A., PIMENTEL, M.M. The relation between frontal and strike-slip shear zones and the regional metamorphism and magmatism in a deep-crustal segment of the northern Ribeira-Belt, SE-Brazil. In: IBTA, International Conference on Basement Tectonics, 14. Ouro Preto, MG, Brasil. Extended Abstracts, p. 26-28, 1998.

CUNNINGHAM, D., MARSHAK, S., ALKMIM, F.F. Structural style of basin inversion at mid-crustal levels: two transects in the internal zone of the Brasiliano Araçuaí Belt, Minas Gerais, Brazil. Precambrian Research, v. 77, p. 1-15, 1996.
CUNNINGHAM, D., ALKMIM, F.F., MARSHAK, S. A structural transect across the coastal mobile belt in the Brazilian Highlands (latitude $20^{\circ} \mathrm{S}$ ). Precambrian Research, v. 92, p. 251-275, 1998.

FÉBOLI, W.L., PAES, V.J.C. Carta geológica -folha de Itanhomi (1:100.000). Projeto Leste CPRM/CODEMIG. 2a . Ed. CDROM, 2002.

FÉBOLI, W.L. Carta geológica - folha Governador Valadares (1:100.000). Projeto Leste CPRM/CODEMIG. $2^{\mathrm{a}}$. Ed. CD-ROM, 2002.

FISCHEL, D.P., PIMENTEL, M.M., FUCK, R.A., COSTA, A.G., ROSIERE, C.A. Geology and Sm-Nd Isotopic Data for the Mantiqueira and Juiz de Fora Complexes (Ribeira Belt) inthe Abre Campo-Manhuaçú Region, Minas Gerais, Brazil. In: IBTA, International Conference on Pre-Cambrian and Craton Tectonics / International Conference on Basement Tectonics, 14, Extended Abstracts, p. 21-23, 1998.

HIPPERTT, J., ROCHA, A., LANA, C., EGYDIO-SILVA, M., TAKESHITA, T. Quartz plastic segregation and ribbon development in high-grade striped gnaisses. Journal of Structural Geology, v. 23, p. 67-80, 2001.

NALINI JR., H.A., BILLAL, E., NEVES, J.M.C. Syn-collisional peraluminous magmatism in the Rio Doce region: mineralogy, geochemistry and isotopic data of the Neoproterozoic Urucum Suite (Eastern Minas Gerais state, Brazil). Revista Brasileira de Geociências, v. 30, n. 1, p. 120-125, 2000.

NOCE, C.M., ROMANO, A.W., PINHEIRO, C.M., MOL, V.S., PEDROSA-SOARES, A.C. Mapa geológico - folha Ubá (1:100.000). Projeto Sul de Minas-Etapa I. CODEMIG/UFMG. CD-ROM, 2003.

NOCE, C.M., PEDROSA-SOARES, A.C., SILVA, A.C., ALKMIM, F.F. O embasamento arqueano e paleoproterozóico do OrógenoAraçuaí. Revista Geonomos, v. 15, n. 1, p. 17-23, 2007.

NOCE, C.M., PEDROSA-SOARES, A.C., SILVA, L.C., ARMSTRONG, R., PIUZANA, D. Evolution of polyciclic basement complexes in the Araçuaí orogen on U-Pb SHRIMP data: Implications for Brazil-Africa Links in Paleoproterozoic time. Precambrian Research, v. 159, n. 1-2, p.60-78, 2007 b. PEDROSA-SOARES, A.C., NOCE, C.M., WIEDEMANN, C., PINTO, C.P. The Araçuaí-West-Congo Orogen in Brazil:
An overview of a confined orogen formed during Gondwanaland assembly. Precambrian Research, v. 110, p. 307323, 2001.

PEDROSA-SOARES, A.C., NOCE, C.M., TROUW, R.A.J., HEILBRON, M. (coords). Projeto Sul de Minas - Etapa I: Geologia e Recursos Minerais do Sudeste Mineiro. CODEMIG/UFMG/UFRJ/UERJ, Belo Horizonte, 3 v., 822 p. (+13 mapas em escala 1:100.000 e CD-ROM), 2003.

PEDROSA-SOARES, A.C., NOCE, C.M., ALKMIM, F.F., SILVA, L.C., BABINSKI, M., CORDANI, U., CASTAÑEDA, C. Orógeno Araçuaí: síntese do conhecimento 30 anos após Almeida 1977. Revista Geonomos, v. 15, n. 1, p.1-16, 2007.

PEDROSA-SOARES, A.C., ALKMIM, F.F., TACK, L., NOCE, C.M., BABINSKI, M., SILVA, L.C., MARTINS-NETO, M. Similarities and differences between the Brazilian and African counterparts of the Neoproterozoic Araçuaí-West Congo Orogen. In: PANKHURST, J.R., TROUW, R.A.J., BRITO NEVES, B.B.; DE WIT, M.J.(eds.) West Gondwana: Pre-Cenozoic Correlations across the South Atlantic Region. Geological Society of London, Spec.Publ., v. 294, p. 153-172, 2008.

PERES, G.G., ALKMIM, F.F., JORDTEVANGELISTA, H. The southern Araçuaí belt and the Dom Silvério group: geologic architeture and tectonic significance. Anais da Academia Brasileira de Ciencias, v. 76, p. 771-790, 2004.

RIBEIRO, J.H. Carta geológica - folha Dom Cavati (1:100.000). Projeto Leste CPRM/ CODEMIG. 2a . Ed. CD-ROM, 2002.

ROMANO, A.W., NOCE, C.M. Mapa geológico - folha Muriaé (1:100.000). Projeto Sul de Minas-Etapa I. CODEMIG/UFMG. CD-ROM, 2003.

SIGNORELLI, N. Carta geológica - folha Caratinga (1:100.000). Projeto Leste CPRM/ CODEMIG. 2a. Ed. CD-ROM, 2003.

SCHOBBENHAUS, C., GONÇALVES, J.H., SANTOS, J.O.S., ABRAM, M.B., LEÃO NETO, R., MATOS, G.M.M., VIDOTTI, R.M., RAMOS, M.A.B., JESUS, J.D.A. de (eds.). Carta geológica do Brasil ao milionésimo sistema de informações geográficas. Programa Geologia do Brasil. CPRM, Brasília. CD-ROM, 2004.

TULLER, M.P. Carta geológica - folha Ipanema (1:100.000). Projeto Leste CPRM/CODEMIG. 2 ${ }^{\text {a }}$. Ed. CD-ROM, 2002.

\section{Artigo recebido em 03/07/2008 e} aprovado em $31 / 10 / 2008$. 